\title{
Soft Touch or Heavy Hand? Legislative Approaches for Preventing Invasions: Insights from Cacti in South Africa
}

\author{
Ana Novoa, Haylee Kaplan, Sabrina Kumschick, John R. U. Wilson, and David M. Richardson*
}

\begin{abstract}
The rate of transportation, introduction, dissemination, and spread of nonnative species is increasing despite growing global awareness of the extent and impact of biological invasions. Effective policies are needed to prevent an increase in the significant negative environmental and economic impacts caused by invasive species. Here we explore this issue in the context of the history of invasion and subsequent regulation of cacti introduced to South Africa. We consider seven approaches to restricting trade by banning the following: (1) species already invasive in the region, (2) species invasive anywhere in the world, (3) species invasive anywhere in the world with a climate similar to the target region, (4) genera containing invasive species, (5) growth forms associated with invasiveness, (6) cacti with seed characteristics associated with invasiveness, and (7) the whole family. We evaluate each approach on the basis of the availability and complexity of information required for implementation, including the cost of the research needed to acquire such information, the likely numbers of false positives and false negatives, the likely degree of public acceptance, and the costs of implementation. Following a consultative process, we provide recommendations for how to regulate nonnative cacti in South Africa. The simplest option would be to ban all cacti, but available evidence suggests that most species pose negligible risk of becoming invasive, making this option unreasonable. The other extreme-reactively regulating species once they are invasive-would incur significant control costs, likely result in significant environmental and economic impacts, and limit management goals (e.g., eradication might be unfeasible). We recommended an intermediate option-the banning of all genera containing invasive species. This recommendation has been partly incorporated in South African regulations. Our study emphasizes the importance of scientific research, a legal framework, and participation of stakeholders in assessments. This approach builds awareness, trust, and support, and ensures that all interests are reflected in final regulations, making them easier to implement and enforce.
\end{abstract}

Key words: Biological invasions, nonnative species regulations, ornamental plants, prevention, stakeholders, succulent plants.

Policies for dealing with nonnative and invasive species need to address three broad categories of interventions: prevention of new introductions (reduce introduction risk by improving pre- and at-border controls), eradication of potentially invasive species that are already in the country (reduce species-based invasion debt [sensu Essl et al. 2011] by eradicating established alien species that have already

\footnotetext{
DOI: 10.1614/IPSM-D-14-00073.1

* First, third, fourth and fifth authors: Postdoctoral Researcher, Core Team Member, Associate Professor, and Professor, respectively, Centre for Invasion Biology, Department of Botany and Zoology, Stellenbosch University, Matieland, South Africa; second and fourth authors: Research and Geographical Information Systems Technician, and Science Lead, Invasive Species Programme, South African National Biodiversity Institute, Kirstenbosch Research Centre, Cape Town, South Africa. Corresponding author's E-mail: novoa.perez.ana@gmail.com
}

become invasive or could become invasive in the future), and management of species that are already invasive and where eradication is not feasible or desirable (reduce areabased and impact-based invasion debt [sensu Bennett et al. 2012] by controlling the expansion of invasive species to new areas where they could cause new or higher negative impacts).

Efforts directed at prevention and eradication of invaders that are not yet widespread are the most cost-efficient components of such strategies: the environmental and economic costs of managing well-established invasions often far exceed the costs associated with prevention and eradication (Leung et al. 2002; Simberloff et al. 1997). Nonetheless, most nonnative species policies focus primarily on addressing well-established invasive species and not enough attention is given to the other two categories (Burt et al. 2007; Puth and Post 2005). 


\section{Management Implications}

This article develops a framework for assisting decision-makers in developing effective nonnative species policies.

Using cacti in South Africa as a case study, we consider several general approaches for imposing trade bans and evaluate these on the basis of the complexity of information required for implementation, the likely numbers of false positives and false negatives, the degree of public acceptance, and the costs of research and implementation. Following a consultative process, we provide recommendations that have been partly incorporated in national regulations.

Our study highlights the importance of combining scientific research, stakeholders' opinions, and legal components in developing new nonnative species policies.

One option for limiting invasions through legislation would be to ban the importation and use of all nonnative species. However, many nonnative species are beneficial (e.g., for agriculture, horticulture, or forestry) and most have little chance of becoming invasive and causing problems (Dehnen-Schmutz 2011; Vitousek et al. 1997). Moreover, in many enterprises such as the pet trade and ornamental horticulture, there is a strong demand for an increasing diversity of nonnative species (Dehnen-Schmutz 2011; Smith et al. 2008). At the other extreme, policies could be reactive (dealing with problems once they have arisen), but this approach incurs important future control costs and will likely result in significant environmental and economic impacts.

More moderate options for regulating introductions require (1) some form of explicit elucidation of the risks associated with certain groups of nonnative species and (2) the implementation of specific actions to prevent the transport, introduction, dissemination, and spread of highrisk species. The ideal situation would be to manage each species according to the context, as the likelihood of invasion and consequences of action varies substantially over time and space. However, this is impractical. The key challenge is to find ways of regulating movements of groups of nonnative species that are effective in reducing the threat of biological invasions; are based on objective, transparent, and defendable criteria; enjoy buy-in and support from most stakeholders; are aligned with international, national, and regional policies and priorities and best practice; and stand a chance of being implemented and enforced in real-world situations. Placing nonnative organisms into several broad categories can help to simplify this process (Baker et al. 2005; Burgiel and Perrault 2011). There are three broad types of lists in general use: (1) an invasive species list (indicating that species are already present in the country and recorded as invasive, and that their use is regulated), (2) a prohibited list (indicating that species are not present in the country yet but the risk of invasiveness is high and their introduction is prohibited or subject to particular conditions), and (3) a permitted list (indicating that their risk of becoming invasive is low and that species are approved for being used without restriction).

Achieving the goal of effective and appropriate listing is challenging for many reasons and each group of species has its own set of problems that complicate the implementation of practical regulations. Moreover, challenges relating to the prevention of new invasions through listing are particularly acute for groups that contain species that are commercially or otherwise important and that, in certain instances, provide clear benefits but are harmful in other contexts (benefits and costs typically accruing to different stakeholders). Much attention is being given to dealing with aspects of invasions of groups of nonnative species that have a commercial value on the one hand, but cause damage as invaders on the other. Such cases give rise to a classic conflict of interests, where the benefits accrue to a number of people, while society at large bears the external costs (de Wit et al. 2001; Dickie et al. 2013; van Wilgen and Richardson 2013).

This paper considers a framework for integrating strong trade regulation components in nonnative species policies, using the family Cactaceae in South Africa as an example. We place this in the context of historical efforts to control invasions of cacti in South Africa and elsewhere, and draw conclusions that may be useful for invasive species regulation in general.

\section{Methods}

Study Case. All but one of the more than 1,900 species in the cactus family (Cactaceae; "cacti") are endemic to the Americas. The first nonnative cactus species arrived in South Africa early in the 18th century (Annecke and Moran 1978). Over the following two centuries many species were introduced to produce fruit for human consumption and for livestock fodder (Walters et al. 2011). During the last 60 $\mathrm{yr}$, hundreds of additional species have been introduced to South Africa, almost exclusively for ornamental purposes. This cactus trade is worth an estimated 3.7 million US dollars (40 million Rand) annually (Novoa, Wilson, Le Roux, Richardson, unpublished data).

Many of the introduced species have become naturalized and 35 cactus species are currently formally listed as invasive in South Africa. The threat of cactus invasions in South Africa to biodiversity, ecosystem functioning, resource availability, national economy, and human health has been recognized for well over a century (Walters et al. 2011). The long and interesting history of introduction, use, and conflict of cacti in South Africa makes the Cactaceae an ideal group to study the criteria required for listing taxa for regulation.

Cactus species have been regulated in South Africa since the early 20th century (Table 1). As early as 1911, several 
Table 1. National policies concerning the regulation of cacti in South Africa.

\begin{tabular}{|c|c|c|c|c|}
\hline Regulation & Year & Taxa regulated & $\begin{array}{l}\text { Number of } \\
\text { listed species }\end{array}$ & Regulated species \\
\hline Agricultural Pest Act & 1911 & Single genus & 190 & Opuntia sp. \\
\hline $\begin{array}{l}\text { Conservation of Agricultural } \\
\text { Resources Act (CARA) }\end{array}$ & $\begin{array}{l}1983 \\
\quad \text { (revision) }\end{array}$ & $\begin{array}{c}\text { Currently } \\
\text { invasive } \\
\text { species }\end{array}$ & 14 & $\begin{array}{l}\text { Cereus jamacaru DC., Echinopsis spachiana (Lem.) } \\
\text { Fiedrich and Rowley Harrisia martinii (Labour.) } \\
\text { Britton and Rose, Opuntia aurantiaca Lindl., } \\
\text { Opuntia exaltata A. Berger, Opuntia ficus-indica (L.) } \\
\text { Mill., Opuntia fulgida Engelm., Opuntia humifusa } \\
\text { (Raf.) Raf., Opuntia imbricata (Haw.) DC, Opuntia } \\
\text { lindheimeri Engelm., Opuntia monacantha Haw., } \\
\text { Opuntia spinulifera Salm-Dyck, Opuntia stricta } \\
\text { (Haw.) Haw. and Pereskia aculeata Mill }\end{array}$ \\
\hline $\begin{array}{l}\text { National Environment } \\
\text { Management: Biodiversity } \\
\text { Act, Alien and Invasive } \\
\text { Species Regulation } \\
\text { (NEM:BA) }\end{array}$ & $\begin{array}{l}2008 \\
\quad(\text { draft })\end{array}$ & $\begin{array}{c}\text { Currently } \\
\text { invasive } \\
\text { species }\end{array}$ & 18 & $\begin{array}{l}\text { As for CARA 1983, plus } \\
\text { Hylocereus undatus (Haworth) Britton and Rose, } \\
\text { Opuntia microdasys (Lehm.) Pfeiff., Opuntia robusta } \\
\text { J.C. Wendl., Tephrocactus articulatus (Pfeiff.) } \\
\text { Backeb. }\end{array}$ \\
\hline $\begin{array}{l}\text { National Environment } \\
\text { Management: Biodiversity } \\
\text { Act, Alien and Invasive } \\
\text { Species Regulation } \\
\text { (NEM:BA) }\end{array}$ & $\begin{array}{l}\text { Feb } 2014 \\
\quad(\text { draft })\end{array}$ & Whole family & 1922 & All cactus species \\
\hline $\begin{array}{l}\text { National Environment } \\
\text { Management: Biodiversity } \\
\text { Act, Alien and Invasive } \\
\text { Species Regulation } \\
\text { (NEM:BA) }\end{array}$ & $\begin{array}{l}\text { Aug } \\
2014\end{array}$ & $\begin{array}{l}\text { Currently } \\
\text { invasive } \\
\text { species }+ \\
\text { genera with } \\
\text { many } \\
\text { known } \\
\text { invaders }\end{array}$ & $\begin{array}{l}35 \text { (National } \\
\text { List of } \\
\text { Invasive } \\
\text { Species) }+ \\
292 \text { (List of } \\
\text { Prohibited } \\
\text { Alien } \\
\text { Species) }\end{array}$ & $\begin{array}{l}\text { As for the draft of NEM : BA 2009, plus } \\
\text { Austrocylindropuntia cylindrica (Juss. ex Lam.) } \\
\text { Backeberg., Cereus hexagonus (L.) Mill., Cereus } \\
\text { hildmannianus K. Schum., Cylindropuntia fulgida } \\
\text { (Engelm.) F.M. Knuth var. fulgida, Cylindropuntia } \\
\text { fulgida (Engelm.) F.M. Knuth var. mamillata } \\
\text { (Schott ex Engelm.) Backeb., Cylindropuntia } \\
\text { leptocaulis (DC.) F.M. Knuth, Cylindropuntia } \\
\text { pallida (Rose) F.M. Knuth, Cylindropuntia spinosior } \\
\text { (Englem.) F.M. Knuth, Harrisia balansae } \\
\text { (K. Schum.) N.P. Taylor and Zappi, Harrisia } \\
\text { pomanensis (F.A.C. Weber) Britton and Rose, } \\
\text { Harrisia tortuosa (J. Forbes ex Otto and A. Dietr.) } \\
\text { Britton and Rose, Myrtillocactus geometrizans } \\
\text { (Mart.), Opuntia elata Link and Otto ex Salm- } \\
\text { Dyck, Opuntia leucotricha DC., Opuntia pubescens } \\
\text { J.C. Wendl. ex Pfeiff., Opuntia salmiana J. Parm. ex } \\
\text { Pfeiff., Opuntia tomentosa Salm-Dyck, Peniocereus } \\
\text { serpentinus (Lag. and Rodr.) N.P. Taylor, } \\
\text { Cylindropuntia sp., Harrisia sp., Opuntia sp., and } \\
\text { Pereskia sp. }\end{array}$ \\
\hline
\end{tabular}

Opuntia species were already causing economic problems to South African farmers (Paterson et al. 2011). The identity of those species remains unclear owing to taxonomic and nomenclatural uncertainty and species misidentification that is still prevalent in the family (Annecke and Moran 1978). For example, Opuntia ficus-indica (L.) Mill. (prickly pear) was then known under a range of names, including Opuntia elatior Mill., Opuntia maxima Mill., Opuntia megacantha Salm-Dyck, Opuntia schumannii Weber, and Opuntia tuna Haw. (Walters et al. 2011). Due to this nomenclatural instability and to prevent the introduction of new agricultural pests into South Africa, the Agricultural 
Pest Act of 1911 listed and prohibited the importation of all 190 species in the genus Opuntia.

In 1983, the Conservation of Agricultural Resources Act (CARA) changed the previous genus-level criterion for legislating the management of cactus species, and only the 14 species considered as invasive in South Africa at the time (cactus species capable of reproducing and spreading without the direct assistance of humans) were listed as Category 1 invaders. This meant that no person was allowed to establish, plant, maintain, multiply, propagate, import, sell, or acquire these 14 species.

In the amendment of CARA regulations in 2001 the same 14 species were listed again as Category 1 species (as in 1983). In 2009, a draft of the National Environment Management: Biodiversity Act (NEM:BA) Alien and Invasive Species Regulations was published for public comment. Eighteen cactus species were listed under these draft regulations. This list incorporated the 14 cactus species listed under CARA regulations and added four species. All of them were listed as Category $1 \mathrm{~b}$ ("Invasive species requiring compulsory control as part of an invasive species control programme. These plants are deemed to have such a high invasive potential that infestations can qualify to be placed under a government sponsored invasive species management program. No permits will be issued to introduce or use this species in South Africa."), with the exception of Opuntia robusta H.L. Wendl. ex. Pfeiff. (blue-leaf cactus), which was listed under Category 2 ("Invasive species regulated by area. A demarcation permit is required to import, possess, grow, breed, move, sell, buy or accept as a gift any plants listed as Category 2 plants.") and Tephrocactus articulatus, (Pfeiff.) Backeb. (pine-cone cactus) listed as Category 1a ("Invasive species requiring compulsory control. Any specimens of Category 1a listed species need, by law, to be eradicated from the environment. No permits will be issued to introduce or use this species in South Africa."). During the deliberations for revisions to the NEM:BA regulations in 2014, one proposal was to list the entire Cactaceae family in Category 1b. If this had been enforced, it would have meant that no cactus species could be imported, owned, grown, multiplied, moved around the country, sold, bought, or even received as a gift in South Africa. Given the widespread popularity of cacti in the country, the costs of enforcing this legislation would have been prohibitively high, and it is likely that such strict measures would have generated substantial resistance. The reasons for this shift in regulations were not clearly explained. Clearly, a more rational and practical approach was needed.

Different Approaches to Regulate Cacti. Much work has recently focused on reviewing the invasive performance of particular groups of species in different situations around the world (e.g., Moodley et al. 2013; Potgieter et al. 2013; Richardson et al. 2011; Shackleton et al. 2014). Here, we propose to use insights from this research to define different approaches for the management of a particularly challenging taxonomic group (cacti) in South Africa.

To identify potential approaches for regulating cactus introductions, we reviewed the literature on cacti as invasive species, recorded the number and identity of invasive cacti in South Africa and worldwide, and scrutinized previously proposed approaches for distinguishing levels of invasiveness in the family (see Novoa et al. 2015). From the identified approaches we selected seven that we felt could potentially be implemented. Each of the seven approaches divided the family (comprising 1,922 species) into an invasive list (comprising the 35 species recorded as invasive in South Africa), a prohibited list (comprising those species identified by the criterion as likely to become invasive in South Africa), and nonlisted species (species not identified by the criterion as likely to become invasive in South Africa). We did not compile permitted lists, as they are not accommodated in current South African regulations.

Workshop with Stakeholders. As part of the efforts to engage with stakeholders on the decision-making regarding the regulation of cactus species in South Africa, a workshop was organized by the South African Cactus Working Group (SACWG) in April 2014. SACWG comprises representatives of all major stakeholders directly involved in cactus management and policy implementation, such as the South African National Biodiversity Institute, the South African National Department of Environmental Affairs, and the Agricultural Research Council. Its role is to coordinate cactus management at a national level with the specific objective of drafting a strategic framework to accommodate this aim. During this workshop, the 27 participants were asked to critique each of the proposed approaches for cactus regulation and to identify the most feasible approach for regulating cacti introductions and dissemination.

Criteria for Decision-Making. The suitability of each identified and discussed approach was evaluated with reference to six criteria: (1) level of understanding or amount of information captured by the approach (just trivial or basic information, information about the traits that showed correlation with invasiveness, information about the traits known to cause invasiveness (i.e. with a predictive ability), or information about underlying mechanisms of invasion); (2) costs of getting the information (high, medium, low, or no cost where required information is already available); (3) number of false positives (i.e., number of species considered as potentially invasive when they are not-high, medium, low, or none); (4) number of false negatives (i.e., number 
Table 2. Approaches and rationales for regulating cacti, and implications for South African regulations.

\begin{tabular}{|c|c|c|c|}
\hline Approach & Rationale & $\begin{array}{l}\text { Number of species on the } \\
\text { invasive }+ \text { prohibited list }\end{array}$ & $\begin{array}{c}\text { Number of species } \\
\text { not listed } \\
\end{array}$ \\
\hline $\begin{array}{l}\text { 1. "Currently invasive in the } \\
\text { country" banned }\end{array}$ & Wait and react to problems as they arise. & $35+0$ & 1,887 \\
\hline $\begin{array}{l}\text { 2. "Invasive anywhere in the } \\
\text { world" banned }\end{array}$ & $\begin{array}{l}\text { "Invasive elsewhere" is one of the best } \\
\text { predictors of plant invasiveness (Rejmánek } \\
\text { et al. 2005). }\end{array}$ & $\begin{array}{l}35 \text { (invasive in South Africa) + } \\
23 \text { (invasive elsewhere) }\end{array}$ & 1,864 \\
\hline $\begin{array}{l}\text { 3. "Invasive anywhere in the } \\
\text { world with analogous } \\
\text { climatic conditions to the } \\
\text { target region" banned }\end{array}$ & $\begin{array}{l}\text { Some of the } 23 \text { species invasive elsewhere } \\
\text { might not be invasive in South Africa } \\
\text { because there are no suitable habitats for } \\
\text { them to invade. }\end{array}$ & $\begin{array}{l}35 \text { (invasive in South Africa) }+ \\
0-23 \text { (to be determined) }\end{array}$ & $1,864-1,887$ \\
\hline $\begin{array}{l}\text { 4. "Any genera that contain } \\
\text { invasive species" banned }\end{array}$ & $\begin{array}{l}\text { Just } 13 \text { of the } 130 \text { genera of Cactaceae include } \\
\text { species recorded as invasive. These genera } \\
\text { tend to share characteristics (e.g., prolific } \\
\text { fruiting, vegetative reproduction, spines, } \\
\text { good dispersal mechanisms, and lack of } \\
\text { natural enemies) and have consistently } \\
\text { shown tendencies to become invasive } \\
\text { (Novoa et al. 2014). }\end{array}$ & $\begin{array}{l}35 \text { (invasive in South Africa) + } \\
503 \text { (congeners) }\end{array}$ & 1,384 \\
\hline $\begin{array}{l}\text { 5. "Any growth forms that } \\
\text { contain invasive species" } \\
\text { banned }\end{array}$ & $\begin{array}{l}\text { Cuttings allowing ease of propagation can be } \\
\text { made from just five of the } 12 \text { growth forms } \\
\text { of the family Cactaceae (Anderson 2001) } \\
\text { and these five growth forms (cylindrical, } \\
\text { flattened-padded, sprawling, leaf-like, and } \\
\text { angled) have consistently shown tendencies } \\
\text { to become invasive (Novoa et al. 2014). }\end{array}$ & $\begin{array}{l}35 \text { (invasive in South Africa) + } \\
977 \text { (grow from cuttings) }\end{array}$ & 1,000 \\
\hline 7. "Whole family" banned & $\begin{array}{l}\text { Apply the precautionary principle; avoid } \\
\text { problems before they arise. }\end{array}$ & $\begin{array}{l}35 \text { (invasive in South Africa) + } \\
1,887\end{array}$ & 0 \\
\hline
\end{tabular}

of species considered as not potentially invasive when they actually are-high, medium, low, or none); (5) public acceptance (low, medium, high, or all the stakeholders support the decision); and (6) costs of implementing the regulations based on this approach (high, medium, low, or zero).

\section{Results and Discussion}

Approaches for Regulating Cacti. Seven approaches were identified as options for listing cactus species: (1) any species currently invasive in the country (i.e., 35 currently invasive species); (2) any species invasive anywhere in the world (i.e., 35 currently invasive species +23 species invasive elsewhere in the world); (3) any species invasive anywhere in the world with analogous climatic conditions to the target region (i.e., 35 currently invasive species + those species [from the 23 invasive elsewhere] established [native or invasive] in climatically similar areas); (4) any genera that contain invasive species (i.e., 13 genera [538 species] containing invasive species); (5) any growth form that contain invasive species (i.e., five growth forms [1,012 species] showing tendencies to become invasive); (6) any seed characteristics associated with invasiveness (species with larger seeds [number to be determined]); and (7) the 
whole family (i.e., 1,922 species). The rationale for each approach is shown in Table 2 .

Workshop with Stakeholders. The results of the discussions between stakeholders on using the seven approaches in South Africa were the following:

Only listing currently invasive species would limit conflicts of interest because no nurseries in South Africa trade with any of the species already recorded as invasive. This is in line with current regulations (approach 1). Only a limited number of species would be listed (35 species), making the list easy to manage. However, such a list ignores many potentially invasive species (Novoa et al. 2015), both species already introduced and likely to invade with time and high-risk species yet to be introduced. Therefore criterion 1 alone is inadequate for addressing all components of risk.

Listing species based on invasiveness anywhere (approach 2 ) would also result in a fairly short list (58 species) and could easily be justified to stakeholders. However, despite worldwide introductions of cacti over several centuries, many species have not had the opportunity to display invasive tendencies because of short residence times or because past introductions have been to areas that are suboptimal for establishment and proliferation. Consequently, many potentially invasive cacti would be missed using this criterion. Moreover, as South Africa is one of the three regions with the longest histories of cactus invasions and has relatively high introduced and invasive species richness, approach 2 is essentially still reactive in nature (and better suited to regions with a shorter history of cactus introductions). Modifying approach 2 to take climate into account (approach 3), provides a greater degree of accuracy, but it is also essentially reactive for South Africa; it requires both expertise to run species-by-species bioclimatic models and detailed native range data with which to populate such models (for which data are not always available). Climate change might also alter future suitability.

South Africa historically prohibited the introduction of all taxa in the genus Opuntia (Table 1). As such, approach 4 has a precedent. It is also easier to identify genera than species of cacti and the nomenclatural instability within genera would be less of an issue. Most ornamental species belong to genera that currently do not contain invasive species, which means that the criterion would likely be favorably received by stakeholders. However, there is a wide variation in the species richness of genera. Under a strict interpretation, a single invasive species would lead to an entire genus being banned, and the approach is essentially reactive for monotypic genera (of which there are 35 in the family).

Listing cactus species by growth form (approach 5) would, in contrast to taxonomic approaches, be easy to implement. There would be no problems related to the nomenclatural instability of the family and regulated individuals would be easy to identify and to locate in the nursery trade (no special skills would be needed). However, it is not possible to identify a growth form when plants are introduced as seeds. All potentially invasive species would be regulated. However, many species that are not potentially invasive would also be prohibited.

Most cacti traded internationally, including all new cactus species entering South Africa, are disseminated in the form of seed (Novoa, Wilson, Le Roux, Richardson, unpublished data). Consequently, some scheme of regulation based on seed characteristics (approach 6) is appealing if there is a clear link between seed features and invasiveness. However, information on the seed characteristics is not available for many species of cacti. Compiling such a complete list of seed characteristics and determining correlates between these and invasiveness would involve a major research project. At this time, regulation of cacti in South Africa based on seed characteristics is unfeasible.

Finally, the decision to regulate the whole family (approach 7) would put a significant horticultural industry out of business and would prevent many people from enjoying their passion, despite the fact that most cactus species likely have negligible risk of becoming invasive considering their long residence time and status. In South Africa, more than 200 different cactus species have been introduced by the horticultural trade over the last $60 \mathrm{yr}$ (Novoa, Wilson, Le Roux and Richardson, unpublished data). While such a criterion is appealing for its simplicity of implementation, there would be substantial resistance with the potential to reduce public support for regulations.

The stakeholders represented in the SACWG agreed that regulation at the genus level (approach 4) was currently the most appropriate approach for cactus species in South Africa.

Criteria for Decision-Making. The six assessment criteria were proposed in an initial form to the SACWG and revised after discussions. "Genus level" is the most suitable approach for listing cactus species (Table 3), since it is the approach that generally encompasses the highest levels for each assessment criterion (see Supplemental Material for detailed interpretation of the position of each criterion; http://10.1614/IPSM-D-14-00073.S1).

General Discussion. Most invasions begin with the arrival of a small number of individuals or propagules (Wilson et al. 2009) and the costs of excluding future introductions is usually low relative to the cost and effort of control actions initiated after populations have arrived, established, and spread (Mack et al. 2000; Olson and Roy 2005; Simberloff et al. 1997). Therefore, the approach followed in policies aimed at reducing problems with invasive cacti in South Africa in recent decades, by regulating only those species already invasive in the country, is inadequate. Other countries, including Australia and the United States, have also 
Table 3. Evaluating the cost and feasibility of different approaches for regulating alien species. See Supplementary Material (http:// 10.1614/IPSM-D-14-00073.S1) for details on the placement of each approach relative to the assessment criteria.

\begin{tabular}{|c|c|c|c|c|}
\hline \multirow[b]{3}{*}{ Assessment criteria } & \multicolumn{4}{|c|}{ Feasibility of approach ${ }^{a}$} \\
\hline & - & & & + \\
\hline & & Real world & & Ideal situation \\
\hline A. Level of understanding & $\begin{array}{l}\text { Trivial information } \\
1,7\end{array}$ & $\begin{array}{l}\text { Traits correlated with invasion } \\
2,3,6\end{array}$ & $\begin{array}{l}\text { Traits of invasion } \\
4,5\end{array}$ & $\begin{array}{l}\text { Mechanistic understanding of } \\
\text { invasion }\end{array}$ \\
\hline $\begin{array}{l}\text { B. Costs of getting the } \\
\text { information }\end{array}$ & $\begin{array}{l}\text { High } \\
3\end{array}$ & Medium 6 & $\begin{array}{l}\text { Low } \\
2,4,5\end{array}$ & $\begin{array}{l}\text { The information required is } \\
\text { already available } \\
1,7\end{array}$ \\
\hline $\begin{array}{l}\text { C. Number of false } \\
\text { positives }\end{array}$ & $\begin{array}{l}\text { High } \\
7\end{array}$ & Medium 5, 6 & $\begin{array}{l}\text { Low } \\
2,3,4\end{array}$ & $\begin{array}{l}\text { No false positives } \\
1\end{array}$ \\
\hline $\begin{array}{l}\text { D. Number of false } \\
\text { negatives }\end{array}$ & $\begin{array}{l}\text { High } \\
1,2,3\end{array}$ & Medium 6 & $\begin{array}{l}\text { Low } \\
4,5\end{array}$ & $\begin{array}{l}\text { No false negatives } \\
7\end{array}$ \\
\hline E. Public acceptance & $\begin{array}{l}\text { Low } \\
7\end{array}$ & Medium 5 & $\begin{array}{l}\text { High } \\
1,2,3,4\end{array}$ & $\begin{array}{l}\text { All the stakeholders support } \\
\text { the decision }\end{array}$ \\
\hline F. Costs of implementation & $\begin{array}{l}\text { High } \\
7\end{array}$ & Medium 5 & $\begin{array}{l}\text { Low } \\
2,3,4,6\end{array}$ & $\begin{array}{l}\text { No costs of implementation } \\
1\end{array}$ \\
\hline
\end{tabular}

${ }^{a}$ The numbers in the table refer to the approaches in Table 2: (1) currently invasive in the country, (2) invasive anywhere in the world, (3) invasive anywhere climatically suitable to the target region, (4) any genera that contain invasive species, (5) any growth forms associated with invasiveness, (6) any seed characteristics associated with invasiveness, and (7) whole family.

traditionally adopted an "innocent until proven guilty" approach, but this is changing. Already in 1997, the Australian Quarantine Inspection Service dropped this approach in favor of a risk assessment system for screening new plant imports and the U.S. Department of Agriculture's Animal and Plant Health Inspection Service is also considering a change in its policies. In 2006 the Ecological Society of America recommended that the U.S. federal government should use new information and practices to prevent the transportation, introduction, dispersion and spread of potentially harmful nonnative species (Lodge et al. 2006).

To achieve the goal of prevention and eradication of invaders that are not yet widespread, banning all transportation, introduction, dispersion, and spread of nonnative species would be a simple, but draconian, option. The restriction in the flow of beneficial goods and services related to the regulated species will likely come with a substantial cost of public support. This extreme option is being applied on several islands of the SubAntarctic Biogeographical Region (Villiers et al. 2006) where nonnative species pose no conflict of interests. But in the majority of situations decision-makers must balance the need to prevent potential invasions against the ethical considerations and economic benefits of free trade.
The ideal situation would be to have a mechanistic understanding of invasion allowing us to develop lists of nonnative species with no false positives or negatives, for decisions to be supported by all stakeholders, and for there to be no costs of implementation. But this is unrealistic. What is required is an open, transparent process whereby the options are expressed and the pros and cons of each are identified and discussed (e.g., Kumschick et al. 2012a, for the management of nonnative species). In this paper we propose a decisionmaking protocol (Table 4) based on the achievement of the highest level of understanding with the lowest level of costs involved, the lowest level of false positives and negatives, the highest level of public acceptance, and the lowest level of costs of implementation (Table 3).

To achieve the goal of nonnative species control in realworld situations, it is important to understand the full suite of traits influencing the invasion process. However, in many cases our level of understanding of the situation (Table 3) is low. Therefore the first step to improve our understanding is to identify traits correlated with invasiveness or impact (Kumschick et al. 2012b; Moodley et al. 2013). Although correlates of invasiveness have been shown to be potentially useful for predicting invasions, such correlations do not explain invasions. Recognition of 
Table 4. General process for developing recommendations for regulating invasive taxa, with the example of how it was applied to Cactaceae in South Africa.

Step Example for Cactaceae in South Africa

1. Review group, looking for correlates and mechanistic

See Novoa et al. (2015)

explanations for invasiveness

2. Develop approaches to regulating the group including both Seven approaches considered (see Table 2) generic approaches (e.g., ban whole group), and group-specific approaches (e.g., ban cacti from specific growth forms), and work out implications of each approach

3. Present to stakeholders and, in discussion, assess each approach based on set criteria (indicators)

Meeting of the South African Cactus Working Group held in April 2014. The seven approaches assessed on six criteria, with results in Table 3 and Supplementary Material (http://10.1614/IPSM-D-14-00073.S1) and text.

This paper

the link between functional traits and mechanisms of invasion has stimulated much research to improve traitbased approaches (Drenovsky et al. 2012). Reaching this maximum information level is a complex process that requires a substantial investment in research (criterion 2). In South Africa, regulations relating to cacti have, until now, been based on low-cost but trivial information: just those species that are known as invasive, all species of one genus, or all the species of the family (Table 1). According to the approach advocated here for regulating cacti in South Africa (Table 2), the highest level of understanding is reached by criteria relating to genus level and growth form, which implies low research costs (Table 3).

Moreover, lists of nonnative species have to be accurate (Hulme 2012): the number of false positives (criterion 3) and negatives (criterion 4) must be minimal. As discussed before, regulating species that pose a negligible risk (false positives) at best limits personal freedom and at worse creates conflicts of interest and a distrust of the system, and carries a substantial economic cost in terms of lost opportunities. Failure to regulate nonnative species with high risks of becoming invasive (false negatives) will incur significant control costs, will likely result in significant environmental and economic impacts, and is likely to limit control options. In South Africa the option of only banning recorded invasive cactus species will not include any false positives but will incur a large amount of false negativesseveral species currently not recorded as invasive in South Africa (i.e., species from the genera Harrisia, Cylindropuntia, or Opuntia) are likely to become invasive in the future in the absence of management; see Novoa et al. 2015 for further information), whereas banning the whole family, even with no false negatives involved, will result in a considerably high number of false positives. In this regard, the most accurate approach would be to impose a genus-level ban.

Policies relating to nonnative and invasive species must enjoy the support of the general public (Brody 2003). While it may be cost-effective to regulate transport, introductions, dispersion, and spread, and arguably this is an imperative for signatories of the Convention on Biological Diversity (Olson and Roy 2005), the decision to ban or place conditions on imports and use of nonnative species can restrict international trade and as such may run afoul of international trade agreements (Burgiel and Perrault 2011). Thus, regulations must be transparently developed with stakeholder participation and should embody a clear scientific rationale in their formulation and application. In this study case the decision was discussed among all the stakeholders involved in the SACWG with the aim of minimizing those conflicts. As a result of this discussion, the proposals to ban particular growth forms (regulating more than half of the family Cactaceae, negatively affecting the ornamental trade) and the whole family (not permitting cactus ornamental trade) were the first discarded as they would clearly lead to serious conflicts of interests. The approach of imposing bans at the genus level was once again the most widely supported.

Finally, the proposed regulatory approach must stand a chance of being implemented and enforced. For example, the approach of banning cacti "invasive anywhere in the world with analogous climatic conditions to the target region" was soon discarded since the required distribution data to compute climatic predictions with an acceptable degree of certainty are not available.

In conclusion, banning "any genera that contain invasive species" was considered as the most pragmatic way of regulating the movement of cactus species because it is 
effective in reducing the threat of biological invasions; is based on objective, defendable criteria; enjoys the support from most stakeholders; is aligned with international, national, and regional policies; and is the most likely to be implemented and enforced. Including key parties in this decision-making process with the participation of stakeholders from the beginning increased trust, understanding, and support and ensured that all interests were reflected in the final regulations (Brody 2003). We believe that the setup of scientific research combined with stakeholders' workshops as the SACWG and a final assessment based on the criteria discussed here provides a useful model for providing recommendations (Table 4). Note that the results of our analysis are based on the requirements of current legislation (as defined under the NEM:BA, an invasive species is any alien species whose establishment and spread [1] threaten ecosystems, habitats, or other species or have demonstrable potential to threaten ecosystems, habitats, or other species and [2] may result in economic or environmental harm or harm to human health) and the current level of understanding of the invasiveness of the studied group. All these dimensions will change over time, which means that assessments like this one will need to be repeated at regular intervals (e.g., every $10 \mathrm{yr}$ ).

Following the recommendations presented here, the SACWG proposed that "any genera that contain invasive species" should be banned. This recommendation was, to a large degree, adopted in the final version of the National Environmental Management: Biodiversity Act, Alien and Invasive Species regulations that came into force in October 2014, so that, rather than banning the whole family, restrictions are applied largely on the basis of banning particular genera (Table 1).

\section{Acknowledgments}

We thank all the members of the South African Cactus Working Group for their valuable insights and discussion, and Joseph DiTomaso and two anonymous reviewers for valuable comments. Funding for this work was provided by the Working for Water (WfW) Programme of the South African Department of Environmental Affairs, through the South African National Biodiversity Institute Invasive Species Programme and through the DST-NRF Centre of Excellence for Invasion Biology (C.I•B) (as part of the $\mathrm{C} \cdot \mathrm{I} \cdot \mathrm{B} / \mathrm{WfW}$ collaborative research program on "Research for Integrated Management of Invasive Alien Species"). We acknowledge additional support from the National Research Foundation (grant 85417 to DMR), the Swiss National Science Foundation, and the Drakenstein Trust (to SK).

\section{Literature Cited}

Anderson EF (2001) The Cactus Family. Portland, OR: Timber. 776 p Annecke DP, Moran VC (1978) Critical reviews of biological pest control in South Africa. 2. The prickly pear, Opuntia ficus-indica (L.) Miller. J Entomol Soc South Afr 41:161-188
Baker R, Cannon R, Bartlett P, Barker I (2005) Novel strategies for assessing and managing the risks posed by invasive alien species to global crop production and biodiversity. Ann Appl Biol 146:177-191

Bennett JR, Vellend M, Lilley PL, Cornwell WK, Arcese P (2012) Abundance, rarity and invasion debt among exotic species in a patchy ecosystem. Biol Invasions 15:707-716

Brody SD (2003) Measuring the effects of stakeholder participation on the quality of local plans based on the principles of collaborative ecosystem management. J Plan Educ Res 22:407-419

Burgiel SW, Perrault AM (2011) Black, white and gray lists. Pages 75-77 in Simberloff D, Rejmánek M, eds. Encyclopedia of Biological Invasions. Berkeley and Los Angeles: University of California Press

Burt JW, Muir AA, Piovia-Scott J, Veblen KE, Chang AL, Grossman JD, Weiskel HW (2007) Preventing horticultural introductions of invasive plants: potential efficacy of voluntary initiatives. Biol Invasions 9:909-923

Dehnen-Schmutz K (2011) Determining non-invasiveness in ornamental plants to build green lists. J Appl Ecol 48:1374-1380

De Wit MP, Crookes DJ, van Wilgen BW (2001) Conflicts of interest in environmental management: estimating the costs and benefits of a tree invasion. Biol Invasions 3:167-178

Dickie IA, Bennett BM, Burrows LE, Nuñez ME, Peltzer DA, Porté A, Richardson DM, Rejmánek M, Rundel PW, Wilgen BW (2013) Conflicting values: ecosystem services and invasive tree management. Biol Invasions 16:705-719

Drenovsky RE, Grewell BJ, D’Antonio CM, Funk JL, James JJ, Molinari N, Parker IM, Richards CL (2012) A functional trait perspective on plant invasion. Ann Bot 110:141-153

Essl F, Dullinger S, Rabitsch W, Hulme PE, Hülber K, Jarošík V, Kleinbauer I, Krausmann F, Kühn I, Nentwig W, Vilà M, Genovesi P, Gherardi F, Desprez-Loustau M-L, Roques A, Pyšek P (2011) Socioeconomic legacy yields an invasion debt. Proc Natl Acad Sci U S A 108:203-207

Hulme PE (2012) Weed risk assessment: a way forward or a waste of time? J Appl Ecol 49:10-19

Kumschick S, Bacher S, Dawson W, Heikkilä J, Sendek A, Pluess T, Robinson T, Kuehn I (2012a) A conceptual framework for prioritization of invasive alien species for management according to their impact. NeoBiota 15:69-100

Kumschick S, Bacher S, Blackburn TM (2012b) What determines the impact of alien birds and mammals in Europe? Biol Invasions 15: 785-797

Leung B, Lodge DM, Finnoff D, Shogren JF, Lewis MA, Lamberti G (2002) An ounce of prevention or a pound of cure: bioeconomic risk analysis of invasive species. Proc Biol Sci 269:2407-2413

Lodge DM, Williams S, MacIsaac HJ, Hayes KR, Leung B, Reichard S, Mack RN, Moyle PB, Smith M, Andow DA, Carlton JT, McMichael A (2006) Biological invasions: recommendations for U.S. policy and management. Ecol Appl 16:2035-2054

Mack RN, Simberloff D, Lonsdale WM, Evans H, Clout M, Bazzaz F (2000) Biotic invasions: causes, epidemiology, global consequences and control. Issues Ecol 5:2-22

Moodley D, Geerts S, Richardson DM, Wilson JRU (2013) Different traits determine introduction, naturalization and invasion success in woody plants: Proteaceae as a test case. PLoS One 8:e75078

Novoa A, Le Roux JJ, Robertson MP, Wilson JRU, Richardson DM (2014) Introduced and invasive cactus species: a global review. AoB PLANTS 7:plu078; DOI: 10.1093/aobpla/plu078

Olson LJ, Roy S (2005) On prevention and control of an uncertain biological invasion. Rev Agric Econ 27:491-497

Paterson ID, Hoffmann JH, Klein H, Mathenge CW, Neser S, Zimmermann HG (2011) Biological control of Cactaceae in South Africa. Afr Entomol 19:230-246 
Potgieter LJ, Richardson DM, Wilson JRU (2013) Casuarina: biogeography and ecology of an important tree genus in a changing world. Biol Invasions 16:609-633

Puth LM, Post DM (2005) Studying invasion: have we missed the boat? Ecol Lett 8:715-721

Rejmánek, M, DM Richardson, P Pyek (2005) Plant invasions and invasibility of plant communities. Pages 332-355 in van der Maarel E and Franklin J ed. Vegetation Ecology. John Wiley \& Sons, Ltd. Oxford, UK. DOI: 10.1002/9781118452592.ch13

Richardson DM, Carruthers J, Hui C, Impson FAC, Miller JT, Robertson MP, Rouget M, Le Roux JJ, Wilson JRU (2011) Humanmediated introductions of Australian acacias - a global experiment in biogeography. Divers Distrib 17:771-787

Rojas-Arechiga M, Vazquez-Yanes C (2000) Cactus seed germination: a review. J Arid Environ 44:85-104

Shackleton RT, Le Maitre DC, Pasiecznik NM, Richardson DM (2014) Prosopis: a global assessment of the biogeography, benefits, impacts and management of one of the world's worst woody invasive plant taxa. AoB PLANTS 6:plu027; DOI: 10.1093/aobpla/plu027

Simberloff D, Schmitz DC, Brown TC (1997) Strangers in Paradise: Impact and Management of Nonindigenous Species in Florida. Washington, DC: Island. $479 \mathrm{p}$
Smith KF, Behrens MD, Max LM, Daszak P (2008) U.S. drowning in unidentified fishes: scope, implications, and regulation of live fish import. Conserv Lett 1:103-109

Villiers MS De, Cooper J, Carmichael N, Glass JP, Liddle GM, Mcivor E, Micol T, Roberts A (2006) Conservation management at Southern Ocean Islands: towards the development of best-practice guidelines. Polarforschung 75:113-131

Vitousek PM, D’Antonio CM, Loope LL, Rejmánek M, Westbrooks R (1997) Introduced species: a significant component of human-caused global change. $\mathrm{N} Z \mathrm{~J}$ Ecol 21:1-16

Walters M, Figueiredo E, Crouch NR, Winter PJD, Smith GF, Zimmermann HG, Mashope BK (2011) Naturalised and invasive succulents of southern Africa. Abc Taxa. 359 p

Van Wilgen BW, Richardson DM (2013) Challenges and trade-offs in the management of invasive alien trees. Biol Invasions 16: 721-734

Wilson JRU, Dormontt EE, Prentis PJ, Lowe AJ, Richardson DM (2009) Something in the way you move: dispersal pathways affect invasion success. Trends Ecol Evol 24:136-144

Received October 14, 2015, and approved April 27, 2015.

Associate Editor for this paper: Lisa J. Rew, Montana State University. 